\title{
Stališča osmošolcev v Sloveniji o vlogi vere pri vpli- vu na družbo: analiza podatkov ICCS ${ }^{1}$
}

\section{Attitudes of Eighth-Graders in Slovenia on the Role of Religious Influence in Society: An Analysis of ICCS Data}

Povzetek: V Sloveniji in v nekaterih drugih izobraževalnih sistemih, sodelujočih v Mednarodni raziskavi državljanske vzgoje in izobraževanja (ICCS), smo v vprašalnik za učence vključili vprašanja o vlogi vere pri vplivu na družbo. Rezultati sekundarnih analiz ICCS so pokazali, da imajo osmošolci v Sloveniji ( $N=2844)$, ki pogosteje obiskujejo verske obrede zunaj doma, tudi pozitivnejše mnenje o vlogi vere pri vplivu na družbo. Prav tako so rezultati korelacijskih analiz pokazali na resda šibko, vendar pozitivno in statistično značilno povezanost med pogostostjo obiskovanja verskih obredov zunaj doma s pripravljenostjo prostovoljstva v prihodnje, ne nazadnje tudi s sodelovanjem v prostovoljnih akcijah za pomoč skupnosti sedaj. Zaznana je bila tudi povezava med stališči osmošolcev o vlogi vere pri vplivu na družbo in občutkom evropske identitete osmošolcev v Sloveniji.

Ključne besede: vpliv vere na družbo, prostovoljstvo, participacija v družbi, občutek evropske identitete, osmošolci, ICCS

Abstract: In Slovenia and some other participating education systems in the International Civic and Citizenship Education Study (ICCS), we included questions on the role of religion in influencing society in the Questionnaire for Students. The results of secondary analyses of the ICCS database showed that eighth-graders in Slovenia ( $N=2844)$, who more often attend religious services outside the home with other people, also have a more favourable opinion role about religion in influencing society. The results of correlation analysis also showed a weak but positive and statistically significant association between the frequency of attending religious services outside the home and the willin-

1 Prispevek je rezultat Raziskovalnega programa P5-0106 „Edukacijske raziskave“. 
gness to volunteer in the future, not least by participating in voluntary actions to help the community now. An association was also found between the attitudes of eighth-graders in Slovenia about the role of religion in society and the sense of European identity.

Keywords: endorsement of religious influence in society, volunteering, participation in society, perception of European identity, 8th graders, ICCS

\section{Uvod}

V svetu je danes v šolskem kontekstu državljanska vzgoja priznana kot eno pomembnejših področij za vzgojo posameznika v aktivnega državljana. Pomen tega izseka vzgoje in izobraževanja ni le v smeri usvajanja državljanske vednosti, temveč sta enako pomembna tudi razvoj stališč in pripravljenost za delovanje v (političnem in) družbenem življenju. Pri tem je seveda pomemben tudi razvoj skupnih vrednot za (so)bivanje. Prav zato želimo izpostaviti, da državljanska vzgoja (danes) ne pomeni zgolj politične socializacije kot takšne (še posebno ne politične pismenosti v najožjem razumevanju tega termina), ampak ima mnogo širšo obliko. Del te vzgoje je tudi spoznavanje religij oziroma verstev. ${ }^{2}$ Se pravi: nekako je to družbena pismenost. Na eni strani so vsebine, ki se predajajo mladim posameznikom (npr. tudi v Sloveniji je v okviru obveznega predmeta domovinska in državljanska kultura in etika del učnega načrta, in to za 7. razred osnovne šole, posvečen učnim ciljem/standardom znanja o verovanju, verstvih), na drugi strani pa razvoj vrednot, ki so prav tako skupne tudi nekemu bolj religijskemu pouku (ali pa prevladujočim verstvom po svetu), na primer vrednota strpnosti, moralna načela, etika itd. Skratka, tudi v Sloveniji je to obvezen del kurikula, in prav pri državljanski vzgoji (kakor bi nemara lahko poenostavljeno imenovali to predmetno področje) vključuje cilje, ki so širši od neke zgolj navezave na politiko, politični sistem, pomembni so cilji, ki so pravzaprav družbeni in s svojimi komponentami (kritično mišljenje, razvoj politične in družbene pismenosti, dejavno vključevanje v družbeno življenje) prispevajo k sobivanju posameznikov, ne nazadnje k obstoju družbe.

Podobno analogijo z državljansko pismenostjo (ki ne obsega le državljanske vednosti) lahko vpeljemo tudi za religijsko pismenost. Kakor ugotavljata Dinham in Shawova $(2017,11)$, z vidika religijske pismenosti to pomeni, da sta pomembni poučevanje in učenje tako o religiji kakor o stališčih oziroma prepričanjih (glede religije). Kakor ugotavljata, pri tem ne sme biti pomemben zgolj instrument za kohezijo in državljanstvo, ampak se je nujno ukvarjati s pripravo učečih se na praktično nalogo sodelovanja z bogato raznolikostjo religij in prepričanj, v vsakodnevnem življenju zunaj šole. Pri tem se je treba vprašati, kako mlade na običajen in strpen način poučevati o religiji in o prepričanjih ob drugih šolskih predmetih in

2 Tudi v nadaljevanju članka skušamo dosledno uporabljati termina vera (kot osebno prepričanje) in religija (kot institucionalizirana oblika izražanja vere v skupnosti). Pri citatih upoštevamo terminologijo, ki jo uporabljajo avtorji. 
ob etosu, saj jim to omogoča, da vstopijo v odraslost z razumevanjem religije in prepričanja v svojem življenju in okoli njega, doma in v službi (Dinham in Shaw $2017,11)$. Pri tem sta Globokar in Rifel $(2017,361)$ nekoliko konkretnejša in na podlagi analize izvajanja predmeta vera in kultura v katoliških gimnazijah v Sloveniji ugotavljata, da je po mnenju dijakov religijski pouk pri tem predmetu večinoma «v precejšnji ali zelo veliki meri pomagal, da so celoviteje razumeli sebe in soljudi, kritično vrednotili dogajanje v družbi in postali bolj usposobljeni pri zavzemanju za reševanje perečih osebnih, medosebnih ter življenjskih problemov«.

Pa vendarle, kaj ima to opraviti z udeležbo državljanov v družbenem življenju oziroma s tako imenovano aktivno participacijo $v$ družbi oziroma z državljansko vzgojo, katere pomembni del je očitno tudi usvajanje religijske pismenosti?

Čeprav se zdi, »da izginja religioznost človeka, da religije izgubljajo svoj pomen ali se raztapljajo v postmoderni /.../ spreminjajo se religiozne institucije« (Pevec Rozman 2017, 300), nedavne raziskave kažejo, da je velika večina svetovnega prebivalstva povezana z neko versko tradicijo (Pancer 2015, 72). Članstvo v verski skupini ali organizaciji na več načinov vpliva na državljansko udeležbo: a) verski voditelji in kongreganti postanejo del posameznikove družbene mreže in ta mreža pogosto pomeni vir rekrutiranja za državljanske in politične dejavnosti, b) skoraj vse verske tradicije podpirajo vero v služenje drugim in te vrednote sporočajo svojim privržencem, c) verski voditelji so moralni vzorniki, ki z zavzetostjo za izboljšanje družbe navdihujejo druge, d) vključenost v verske skupine posameznikom omogoča tudi, da se vključijo v široko paleto skupnostnih projektov in se naučijo veščin, ki jih je mogoče uporabiti v drugih civilnih organizacijah in dejavnostih (72-73). Skratka, iz gornjega zapisa je razvidno, da ima vključenost v neko versko tradicijo za posameznika mnoge potencialne vplive, ki segajo ven iz ozkega prakticiranja verske tradicije, v različne sfere družbenega življenja, ne nazadnje tudi na področje aktivnega udejstvovanja $v$ družbi.

Kakor kažejo raziskave, je religija pogosto pomemben katalizator državljanske participacije (Pancer 2015; Schulz et al. 2016, 26). Kako? Verska prepričanja in prakse ljudi so povezani z vsemi oblikami državljanske udeležbe (Pancer 2015, 58). Tako so, na primer, številne študije pokazale na povezavo med religijo in prostovoljstvom - sociologa Smith in Faris sta, denimo, preučila podatke iz raziskave, opravljene na nacionalno reprezentativnem vzorcu ameriških srednješolcev, da bi ugotovila povezavo med religijo in skupnostno dejavnostjo. Ugotovila sta: dijaki, ki so vsak teden obiskovali verske obrede, imajo več kakor dvakrat večjo verjetnost, da bodo redno sodelovali v skupnostnih zadevah ali prostovoljnem delu, v primerjavi z dijaki, ki nikoli ne obiskujejo verskih obredov (58). Religija je prav tako povezana s politično participacijo, kakor povzema Pancer $(2015,58)$ : Zaff in sodelavci (2003) so na podlagi longitudinalne raziskave v ZDA ugotovili, da je bilo pri mladih, ki so se v 10. razredu (to bi v Sloveniji pomenilo začetek srednje šole) udeleževali verskih obredov, za $24 \%$ bolj verjetno, da bodo čez štiri leta (op. p.), ko pridobijo volilno pravico, glasovali na volitvah, kakor mladi, ki na omenjeni stopnji formalnega izobraževanja niso obiskovali verskih obredov (Pancer 2015, 58). Pomembno ugotovitev, ki se prav tako veže na presek religije in političnega delo- 
vanja, najdemo tudi pri Udoviču $(2020,145)$ : v članku, ki analizira maše za domovino, opozori, da je odnos mladih do maše za domovino pomemben predvsem zato, ker bodo mladi kmalu postali politični odločevalci, pri tem pa se bodo njihova sedanja stališča "pretopila tudi v stališča političnih strank, katerih člani bodo".

$\checkmark$ članku se drugače ne osredotočamo na religijski pouk v Sloveniji ali Evropi, bolj nas zanima, kakšna stališča imajo osmošolci v Sloveniji (in v drugih evropskih državah oziroma šolskih sistemih) do vloge vere pri vplivu na družbo. Še posebej nas pa zanima, ali imajo osmošolci, ki se pogosteje udeležujejo verskih obredov zunaj svojega doma z drugimi ljudmi, nemara bolj pozitivna stališča do te vloge pri vplivu na družbo. Na reprezentativnih podatkih za Slovenijo bomo preverili tudi druge hipoteze, ki jih izpeljujemo iz zgoraj opisanih rezultatov tujih raziskav (na primer povezava z obiskovanjem verskih obredov in prostovoljstvom, povezava verskih obredov in politične participacije - vezano na udeleževanje volitev $v$ prihodnje). Ne nazadnje, raziskali bomo tudi povezavo z občutkom evropske identitete, kakor jo definira mednarodna raziskava ICCS.

\section{Vprašanja o vlogi vere pri vplivu na družbo (ICCS 2016)}

Prva mednarodna raziskava s fokusom na državljanski vzgoji in izobraževanju je bila v svetu izvedena leta 1971 (v sklopu Študije šestih predmetov), nato pa kot samostojna raziskava leta 1999 (kratica CivEd - Civic Education Study), leta 2009 in leta 2016 (ICCS - International Civic and Citizenship Education Study) (Klemenčič, Mirazchiyski in Novak 2019, 17-18). Slovenija je sodelovala v zadnjih treh zajemih podatkov, se pravi leta 1999, leta 2009 in leta 2016. ${ }^{3}$ Teme, ki se navezujejo na religijo oziroma vero, so pomemben del raziskave. Tako že pri sami definiciji skupnosti eden od delov opredeljuje članstvo v neki skupnosti, to pa je določeno s prepričanjem posameznika o njegovem članstvu (na primer z identifikacijo s, somišljeniki' glede političnih, verskih, filozofskih ali družbenih vprašanj) (Schulz et al. 2016, 15). Še bolj je pa to razvidno iz same vsebine vprašalnikov in iz testa državljanske vednosti, na primer pri vsebinski domeni družba in njeni podsistemi se raziskava osredotoča tudi na civilne institucije, ki omogočajo prevzemanje različnih vlog v družbi (Klemenčič, Mirazchiyski in Novak 2019, 27): eden od sklopov je namenjen religijskim institucijam (Schulz et al. 2016, 16). Pri državljanskih principih (pri subdomeni vladavine prava) je enako: $v$ smislu enakosti pred zakonom, ne glede na versko prepričanje (16), ali to, da se vsi ljudje rodijo enaki, v smislu dostojanstva in pravic, ne glede na to, kakšne so njihove osebne lastnosti (na primer vera) (20). Ocenjevalni okvir raziskave ICCS definira zelo pomembno dimenzijo v okviru preverjanja državljanske vzgoje in izobraževanja. Govori o različnih tipih percepcij učencev in njihovega vedenja, ki so pomembni pri vzgoji državljana. Ena

Na mednarodni ravni raziskavo koordinira Mednarodna zveza za evalvacijo izobraževalnih dosežkov (IEA oziroma The International Association for the Evaluation of Educational Achievement), v Sloveniji Pedagoški inštitut. 
od teh afektivno-vedenjskih domen so stališča (druga delovanje). Raziskava ICCS znotraj sklopa preverjanja stališč učencev do družbe in do državljanskih sistemov izpostavi poseben sklop, namenjen stališčem o vplivu vere na družbo. To je mednarodna opcija, za katero ni nujno, da jo sodelujoče države (oziroma izobraževalni sistemi) vključijo v raziskavo na nacionalni ravni. V Sloveniji smo ta del vprašalnika izvedli prvič prav v ciklu raziskave 2016. V tem članku se bomo večinoma posvetili prav temu sklopu.

$\checkmark$ tabeli 1 predstavljamo rezultate o stališčih osmošolcev v Sloveniji do vloge vere pri vplivu na družbo. ${ }^{4}$ Učenci so pri tej nalogi lahko izbirali med štirimi kategorijami strinjanja s posamezno postavko (Likertova 4-stopenjska lestvica), in to od zelo se strinjam do nikakor se ne strinjam.

\begin{tabular}{|c|c|c|c|c|}
\hline & Zelo se strinjam & Strinjam se & Ne strinjam se & $\begin{array}{c}\text { Nikakor se ne } \\
\text { strinjam }\end{array}$ \\
\hline $\begin{array}{c}\text { Vera je zame bolj po- } \\
\text { membna kakor to, kar } \\
\text { se dogaja v državni } \\
\text { politiki. }\end{array}$ & $14,4 \%(0,96)$ & $31,8 \%(1,16)$ & $34 \%(1,11)$ & $19,9 \%(0,95)$ \\
\hline $\begin{array}{c}\text { Vera mi pomaga pri } \\
\text { odločanju o tem, kaj je } \\
\text { prav in kaj ni. }\end{array}$ & $14,5 \%(0,82)$ & $34,7 \%(0,88)$ & $29,4 \%(0,95)$ & $21,5 \%(0,92)$ \\
\hline $\begin{array}{c}\text { Verski voditelji bi morali } \\
\text { imeti več vpliva na } \\
\text { družbo. }\end{array}$ & $7,4 \%(0,61)$ & $28,1 \%(0,97)$ & $41,4 \%(1,02)$ & $23,1 \%(0,98)$ \\
\hline $\begin{array}{c}\text { Vera bi morala vplivati } \\
\text { na to, kako se ljudje } \\
\text { vedejo drug do drugega. }\end{array}$ & $13,5 \%(0,80)$ & $39,5 \%(1,09)$ & $27,20 \%(0,85)$ & $19,9 \%(0,82)$ \\
\hline $\begin{array}{c}\text { Življenjska pravila, ki } \\
\text { temeljijo na veri, so } \\
\text { pomembnejša kakor } \\
\text { pravila civilnega prava. }\end{array}$ & $\begin{array}{c}7 \% \\
(0,56)\end{array}$ & $26,3 \%(0,97)$ & $44,3 \%(1,03)$ & $22,4 \%(0,99)$ \\
\hline $\begin{array}{c}\text { Vsi ljudje bi morali imeti } \\
\text { svobodo, živeti } \\
\text { v skladu z vero, } \\
\text { ki jo sami izberejo. }\end{array}$ & $45,8 \%(1,07)$ & $37 \%(1,02)$ & $9,8 \%(0,62)$ & $7,4 \%(0,65)$ \\
\hline $\begin{array}{c}\text { Verni ljudje so boljši } \\
\text { državljani. }\end{array}$ & $8,9 \%(0,62)$ & $18,8 \%(0,82)$ & $40,1 \%(1,13)$ & $32,2 \%(1,05)$ \\
\hline
\end{tabular}

Tabela 1: Stališča osmošolcev v Sloveniji do vloge vere pri vplivu na družbo. Vir: Baza ICCS 2016, naši lastni izračuni. Opomba: standardne napake so navedene v oklepajih ob odstotkih učencev.

Iz rezultatov tabele vidimo, da se je največ osmošolcev v Sloveniji zelo strinjalo s trditvijo, da bi vsi ljudje morali imeti svobodo, živeti v skladu z vero, ki jo sami izberejo (približno 46 \% osmošolcev). Prav tako se jih je z omenjeno postavko stri-

4 Pri postavkah v slovenskem jeziku smo uporabljali termin vera, v smislu človekovega osebnega odnosa z Bogom (oziroma z bogovi v nekaterih verstvih), in ne nekoliko širše oziroma splošnejše in bolj neosebne terminologije, kakor je izraz religija. Prav zato pri identifikaciji postavk uporabljamo termin, ki je bil dejansko uporabljen v Vprašalniku za učence, iz katerega črpamo podatke za našo analizo. 
njalo okoli $37 \%$. Da so verni ljudje boljši državljani, se večina učencev ni strinjala oziroma nikakor ni strinjala (prvo kategorijo je izbralo okoli 40 \% osmošolcev in drugo okoli 32 \%). Odgovori učencev pri preostalih postavkah so nekoliko bolj razpršeni med kategorijami (ne)strinjanja. Pa vendarle vidimo, da se precejšen delež osmošolcev v Sloveniji strinja ali zelo strinja s postavkami, da je vera zanje pomembnejša kakor to, kar se dogaja v državni politiki, da jim vera pomaga pri odločanju o tem, kaj je prav in kaj ni, in da bi vera morala vplivati na to, kako se ljudje vedejo drug do drugega. Pri tem velja posebej opozoriti, da ta tabela ne razlikuje med osmošolci, ki so dejansko verni, in tistimi, ki niso. Ta vidik (drugače vezan na obiskovanje verskih obredov zunaj doma z drugimi ljudmi) podrobneje analiziramo v nadaljevanju članka.

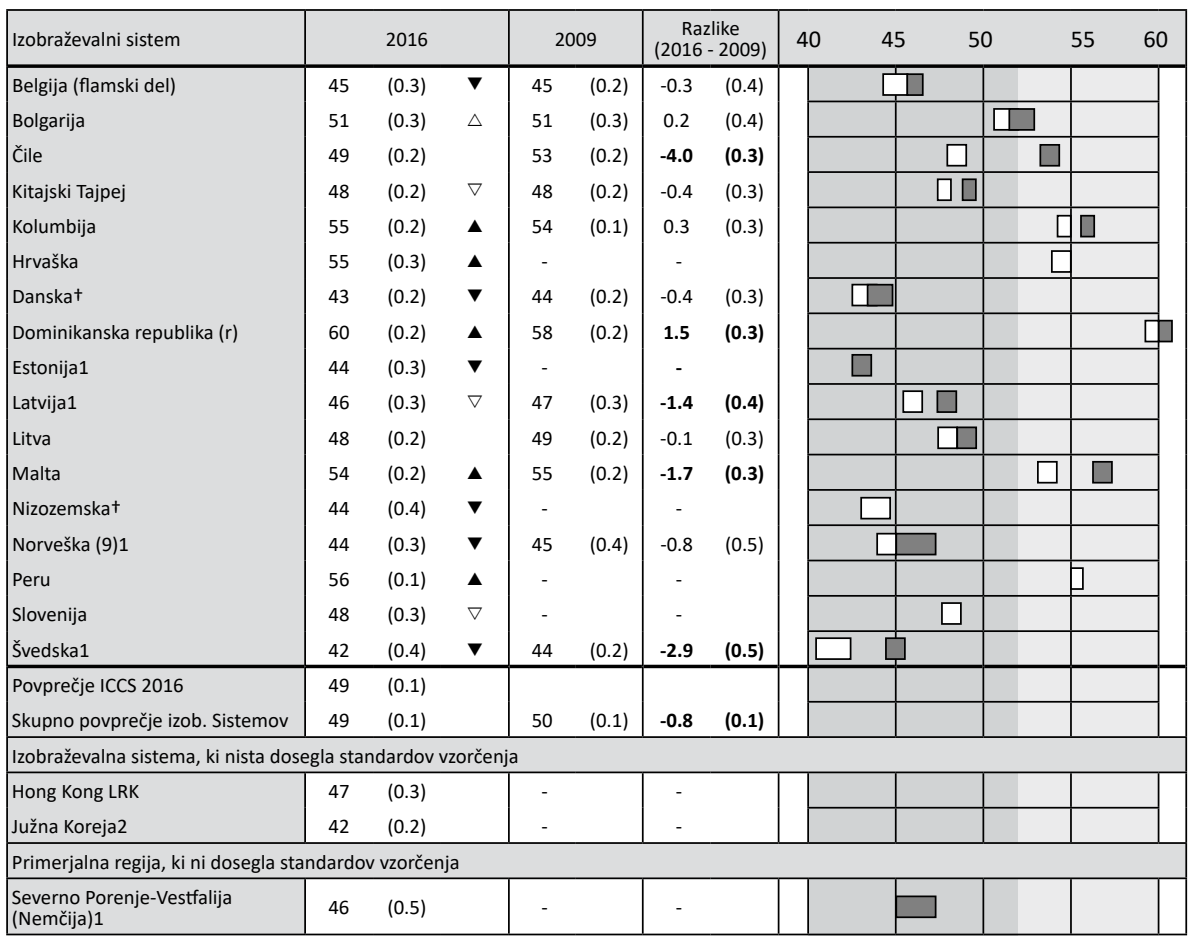

Nacionalni rezultati ICCS 2016 so: Več kot 3 točke nad ICCS povprečjem Statistično značilno nad ICCS povprečjem Statistično značilno pod ICCS povprečjem Več kot 3 točke pod ICCS povprečjem
2016 povprečni rezultat $+/$ - interval zaupanja 2009 povprečni rezultat +/- interval zaupanja $\checkmark$ povprečju imajo učenci z vrednostjo znotraj tega območja več kot $50 \%$ možnosti, da na vprašanje o religijskemu vplivu $v$ družbi odgovorijo z

Nestrinjanje s pozitivnimi trditvami Strinjanje z pozitivnimi trditvami

Slika 1: Stališča o vlogi vere pri vplivu na družbo pri osmošolcih v Sloveniji in Evropi. Vir: prirejeno po Schulz et al. 2018, 140. 
Na sliki vidimo prikaz lestvice, ki je izračunana iz prvih šestih postavk, prikazanih v tabeli 1 . Iz slike 1 vidimo rezultate, izračunane na podlagi te lestvice, prav tako pa tudi trende (nekateri izobraževalni sistemi, ne pa tudi Slovenija, so ta vprašanja vključili že v izvedbo raziskave leta 2009). Najprej si poglejmo trende med letoma 2009 in 2016 . Učenci (osmošolci) iz dvanajstih izobraževalnih sistemov so odgovarjali na ista vprašanja tako leta 2009 kakor leta 2016. Na podlagi tega vidimo, da so učenci iz Dominikanske republike vlogi vere pri vplivu na družbo leta 2016 pripisali večji vpliv kakor v zajemu podatkov predtem. Na drugi strani pa vidimo, da je večina učencev v letu 2016 pripisali vlogi vere manjši vpliv v primerjavi z letom 2009 (statistično pomembne razlike so razvidne pri tistih številkah, ki so zapisane krepko). Tako je bilo, denimo, pri učencih iz Čila, iz Latvije, z Malte in iz Švedske. Podobno je tudi z mednarodnim povprečjem. Kar vidimo iz prikaza, je tudi to, da je med osmošolci v sodelujočih izobraževalnih sistemih odnos do tega, kakšno vlogo ima vera pri vplivu na družbo, različen (razpršenost je kar velika). Mnenje osmošolcev v Sloveniji je pod mednarodnim povprečjem, to pa pomeni, da naši osmošolci niso ocenili tako velike vloge vere pri vplivu na družbo kakor, denimo, njihovi vrstniki iz Hrvaške ali z Malte (če omenimo le ti dve evropski državi). Prav to nas je spodbudilo k nadaljnjemu raziskovanju te teme, zato smo opravili vrsto sekundarnih analiz, ki jih predstavljamo v nadaljevanju.

\section{Analitični okvir in rezultati}

\subsection{Okvir za analizo, postopki}

Okvir za analizo so podatki mednarodne raziskave ICCS 2016, ki so bili v Sloveniji zbrani pred poletjem 2016, prvič javno objavljeni konec leta 2017, s sprostitvijo mednarodne baze v letu 2018. V Sloveniji je v raziskavi sodelovalo 135 šol oziroma 2844 osmošolcev (realizacija vzorca je reprezentativna, to pomeni, da lahko govorimo o rezultatih na ravni populacije osmošolcev v Sloveniji). ${ }^{5}$

Za odgovore na vprašanja o povezanosti stališč osmošolcev o vlogi vere pri vplivu na družbo, vere kot katalizatorja državljanske participacije in pogostosti prostovoljstva, glede na pogostost obiskovanja verskih obredov zunaj doma z drugimi ljudmi, smo izvedli korelacijske analize. Na koncu empiričnega dela nas je tudi zanimala povezava med stališči o vplivu vere na družbo in zaznano evropsko identiteto; tudi tukaj smo izvedli korelacijsko analizo. Vprašanja, katerih podatke analiziramo v članku, so bila vključena v Vprašalnik za učence, postavljena so bila tako, da so pri postavkah učenci izbirali svoje odgovore na 4-stopenjski Likertovi lestvici (podrobneje jih opisujemo pri rezultatih vsake od analiz). Preden so bile izračunane lestvice oziroma korelacije med spremenljivkami, je bilo opravljeno nasprotno kodiranje spremenljivk, da smo dobili vrednosti, ki so imele isto smer (druga-

Sodelovali so tudi učitelji in ravnatelji, vendar njihovih podatkov v tem članku ne analiziramo, ker za vsebino tega članka niso relevantni. 
če analize, primerjave ne bi bile pravilne). Za analizo podatkov smo uporabili programsko orodje RALSA (Mirazchiyski in INERI 2020), ki upošteva kompleksni dizajn in kompleksno vzorčenje raziskave ICCS.

\subsection{Rezultati in interpretacija}

\subsubsection{Osmošolci s pozitivnejšimi stališči o vlogi vere pri vplivu na družbo}

V naši analizi nas je najprej zanimala morebitna povezava med pogostostjo obiskovanja verskih obredov zunaj doma z drugimi ljudmi in stališča osmošolcev o vlogi vere pri vplivu na družbo. V analizi smo izračunali Spearmanovo korelacijo, in to med lestvico "Stališča osmošolcev o vlogi vere pri vplivu na družbo« (S_RELINF) in pogostostjo obiskovanja verskih dogodkov zunaj doma z drugimi ljudmi. Lestvica S_RELINF je oblikovana na podlagi prvih šestih postavk, ki smo jih navedli v tabeli 1: vera je zame bolj pomembna kakor to, kar se dogaja v državni politiki; vera mi pomaga pri odločanju o tem, kaj je prav in kaj ni; verski voditelji bi morali imeti več vpliva v družbi; vera bi morala vplivati na to, kako se ljudje vedejo drug do drugega; življenjska pravila, ki temeljijo na veri, so pomembnejša kakor pravila civilnega prava; vsi ljudje bi morali imeti svobodo, živeti v skladu z vero, ki jo sami izberejo. Kakor že navedeno, je bila kategorija odgovorov 4-stopenjska Likertova lestvica (od zelo se strinjam do nikakor se ne strinjam).

Preverili smo korelacijo (izračunali Spearmanov koeficient korelacije rangov) med omenjeno lestvico in vprašanjem o pogostosti udeleževanja verskih obredov zunaj doma z drugimi ljudmi. Osmošolce smo namreč vprašali prav to, obenem pa smo jim ponudili naslednje kategorije odgovorov, ki zadevajo pogostost udeleževanja omenjenih obredov: nikoli, manj kakor enkrat na leto, vsaj enkrat na leto, vsaj enkrat na mesec, vsaj enkrat na teden.

\begin{tabular}{|c|c|c|c|}
\hline & $\begin{array}{c}\text { Korelacija s pogostostjo obiskovanja } \\
\text { verskih obredov zunaj doma } \\
\text { z drugimi ljudmi }\end{array}$ & $\begin{array}{c}\text { Standardna } \\
\text { napaka }\end{array}$ & p-vrednost \\
\hline $\begin{array}{c}\text { Stališča osmošolcev o } \\
\text { vplivu vere na družbo }\end{array}$ & 0,53 & 0,02 & $<0,001$ \\
\hline
\end{tabular}

Tabela 2: Korelacija pogostosti obiskovanja verskih obredov in stališč o vplivu vere na družbo med osmošolci V Sloveniji. Vir: Baza ICCS 2016, naši lastni izračuni.

Rezultati analize (tabela 2) so pokazali, da je korelacija pozitivna in dokaj močna $(0,53$, s standardno napako 0,02$)$ in je statistično značilna $(p<0,001)$. To pomeni, da imajo osmošolci, ki pogosteje obiskujejo verske obrede zunaj doma, tudi pozitivnejše mnenje o vlogi vere pri vplivu na družbo.

\subsubsection{Religija oziroma vera kot katalizator državljanske participacije - prostovoljstvo, politična participacija}

V uvodnem delu članka smo povzeli rezultate nekaterih drugih raziskav, ki pričajo o pomenu religije oziroma vere kot pomembnega katalizatorja za državljansko 
participacijo. Zato bomo v nadaljevanju analizirali povezavo med pogostostjo udeleževanja pri verskih obredih zunaj doma in stališči o prostovoljstvu v prihodnje oziroma dosedanje sodelovanje v prostovoljskih dejavnostih za pomoč skupnosti, prav tako pa tudi povezavo med pogostostjo udeleževanja pri verskih obredih zunaj doma in politično participacijo.

V Spearmanovi korelacijski analizi smo uporabili že prej opisano spremenljivko pogostosti obiskovanja verskih obredov zunaj doma z drugimi ljudmi in spremenljivki o prostovoljstvu. Znotraj vprašanja »Kako pogosto sodeluješ pri dejavnostih organizacij, klubov oziroma skupin«, na katero so osmošolci odgovarjali tako, da so izbrali eno od treh ponujenih kategorij odgovorov (da, sodeloval sem v zadnjih dvanajstih mesecih; da, sodeloval sem, toda pred več kakor letom dni, in ne, nikdar nisem sodeloval), je bila tudi postavka: „Prostovoljna skupina, ki dela za pomoč skupnosti«. Drugo vprašanje, vezano na pričakovano participacijo na volitvah in v drugih organizacijah v prihodnje (ko bodo ti učenci odrasli, pri volitvah je to, na primer, že približno štiri leta po tem, ko so bili testirani), je prav tako vsebovalo postavko o prostovoljstvu: »Prostovoljno pomagal ljudem v lokalni skupnosti«. Glede na to, kako je bilo vprašanje zastavljeno, je to pomenilo: v prihodnje. Pri tem vprašanju so bile možne kategorije odgovorov: to bi zagotovo naredil; to bi verjetno naredil; tega verjetno ne bi naredil; tega zagotovo ne bi naredil.

\begin{tabular}{|c|c|c|c|}
\hline & $\begin{array}{c}\text { Korelacija s pogostostjo obiskovanja } \\
\text { verskih obredov zunaj doma z drugimi } \\
\text { ljudmi }\end{array}$ & $\begin{array}{c}\text { Standardna } \\
\text { napaka }\end{array}$ & p-vrednost \\
\hline $\begin{array}{c}\text { Sodelovanje v prosto- } \\
\text { voljni skupini, ki dela za } \\
\text { pomoč skupnosti }\end{array}$ & 0,11 & 0,02 & $<0,001$ \\
\hline $\begin{array}{c}\text { Pripravljenost, prosto- } \\
\text { voljno pomagati ljudem } \\
\text { v lokalni skupnosti v } \\
\text { prihodnje }\end{array}$ & 0,14 & 0,02 & $<0,001$ \\
\hline
\end{tabular}

Tabela 3: Korelacija med pogostostjo obiskovanja verskih obredov in prostovoljstvom osmošolcev v Sloveniji. Vir: Baza ICCS 2016, naši lastni izračuni.

Spearmanova korelacija med pogostostjo obiskovanja verskih obredov zunaj doma z drugimi ljudmi in sodelovanjem v prostovoljni skupini, ki dela za pomoč skupnosti, je resda šibka $(0,11$; s standardno napako 0,02$)$, a je statistično značilna $(p<0,001)$. Korelacija med odgovori osmošolcev na pogostost obiskovanja verskih obredov in pripravljenostjo, prostovoljno pomagati ljudem v lokalni skupnosti v prihodnje, je prav tako resda šibka $(0,14$, s standardno napako 0,02$)$, čeprav je tudi tukaj povezava statistično značilna $(p<0,001)$. To pomeni, da bodo osmošolci (takšna so vsaj bila njihova stališča ob izvajanju raziskave), ki pogosteje obiskujejo verske obrede z drugimi ljudmi zunaj svojih domov, pogosteje prostovoljno sodelovali v svojih lokalnih skupnostih (vendar korelacija ni tako močna).

V nadaljevanju sta nas zanimala še dva vidika politične participacije v prihodnje; v analizah smo uporabili dve lestvici: 
- pričakovana elektorska participacija v prihodnje - ta lestvica je sestavljena iz naslednjih postavk: glasovanje na lokalnih volitvah, glasovanje na nacionalnih volitvah, pridobitev informacij o kandidatih pred glasovanjem na volitvah;

- pričakovana aktivna politična participacija v prihodnje - ta lestvica je sestavljena iz naslednjih postavk: pomoč kandidatu ali stranki med volilno kampanjo, pridružiti se politični stranki, pridružiti se sindikatu, kandidirati na lokalnih volitvah, vključiti se v organizacijo, ki ima politične ali dobrodelne namene.

Pri postavkah obeh lestvic so kategorije možnih odgovorov naslednje: to bi zagotovo naredil, to bi verjetno naredil, tega verjetno ne bi naredil, tega zagotovo ne bi naredil.

\begin{tabular}{|c|c|c|c|}
\hline & $\begin{array}{c}\text { Korelacija s pogostostjo obiskovanja } \\
\text { verskih obredov zunaj doma z drugi- } \\
\text { mi ljudmi }\end{array}$ & $\begin{array}{c}\text { Standardna } \\
\text { napaka }\end{array}$ & p-vrednost \\
\hline $\begin{array}{c}\text { Pričakovana elektorska } \\
\text { participacija osmošolcev }\end{array}$ & 0,12 & 0,02 & $<0,001$ \\
\hline $\begin{array}{c}\text { Pričakovana aktivna politič- } \\
\text { na participacija osmošolcev }\end{array}$ & 0,05 & 0,02 & 0,033 \\
\hline
\end{tabular}

Tabela 4: Korelacija med pogostostjo obiskovanja verskih obredov in pričakovano (politično) participacijo osmošolcev v Sloveniji v prihodnje. Vir: Baza ICCS 2016, naši lastni izračuni.

V tabeli 4 prikazujemo rezultate Spearmanove korelacijske analize med pogostostjo obiskovanja verskih obredov osmošolcev in pričakovano udeležbo na volitvah v prihodnosti (se pravi: elektorsko participacijo) - povezava je šibka $(0,12$; s standardno napako 0,02$)$, čeprav je statistično značilna $(p<0,001)$. Povezava pogostosti obiskovanja verskih obredov učencev in prihodnje politične udeležbe je še šibkejša $(0,05$; s standardno napako 0,02$)$, čeprav je tudi tukaj statistično značilna ( $p=0,033)$. Iz teh rezultatov lahko sklepamo, da bodo osmošolci, ki pogosteje obiskujejo verske obrede zunaj doma, bolj verjetno udeleženi na volitvah kakor pa neposredno v politiki. Vendar je korelacija precej šibka.

\subsubsection{Povezava med stališči o vlogi religije pri vplivu na družbo in evropsko identiteto}

Kakor so pokazali rezultati raziskave, opravljene na priložnostnem vzorcu 149 mladostnikov, starih med 15 do 22 let (se pravi: od začetka srednje šole do praviloma vključenosti v 1 . bolonjsko stopnjo študija), h kulturni razsežnosti evropske identitete najpomembneje prispeva religiozna identiteta (Golob, Makarovič in Tomšič 2019, 166;169). V naši bazi imamo dva sklopa spremenljivk, na podlagi katerih lahko za populacijo osmošolcev v Sloveniji izračunamo povezavo med občutkom evropske identitete in stališči o vlogi vere pri vplivu na družbo. ${ }^{6}$

6 Seveda je treba povedati, da je naš konstrukt evropske identitete drugačen kakor v omenjeni raziskavi, ki pa nam je vendarle dala idejo za ta del našega članka. 
Pri tej analizi smo izračunali Pearsonovo korelacijo med lestvico S_RELINF (stališča osmošolcev o vlogi vere pri vplivu na družbo - to je lestvica, ki smo jo uporabili tudi pri prvi analizi) in lestvico E_EUIDENT (lestvica, ki je pri osmošolcih merila občutek evropske identitete). Izračunana je na podlagi vprašanja, ki je bilo vključeno v tako imenovani Evropski modul raziskave ICCS 2016. Lestvico evropske identitete osmošolcev sestavljajo naslednje postavke: sebe imam za Evropejca; ponosen sem, da živim v Evropi; počutim se kakor del Evrope; sebe imam najprej za državljana Evrope, potem pa za državljana sveta. Učenci so pri teh postavkah lahko izbirali med štirimi možnimi kategorijami odgovorov: zelo se strinjam, strinjam se, ne strinjam se, nikakor se ne strinjam.

\begin{tabular}{|c|c|c|c|}
\hline & $\begin{array}{c}\text { Korelacija s stališči učencev o vlogi } \\
\text { vere pri vplivu na družbo }\end{array}$ & Standardna napaka & $p$-vrednost \\
\hline $\begin{array}{c}\text { Občutek evropske } \\
\text { identitete }\end{array}$ & 0,07 & 0,02 & $\mathrm{p}<0,001$ \\
\hline
\end{tabular}

Tabela 5: Korelacija med stališči osmošolcev v Sloveniji o vplivu vere na družbo in občutkom evropske identitete. Vir: Baza ICCS 2016, naši lastni izračuni.

Korelacija med obema lestvicama je precej šibka $(0,07$; s standardno napako $0,02)$, čeprav je statistično značilna $(p<0,001)$. To pomeni, da obstajajo učenci, ki se strinjajo s tem, da ima vera vpliv na družbo, in se ponavadi opredelijo za evropske državljane, vendar v dokaj majhni meri. Skratka, kljub šibkost korelacije sta ta dva sklopa stališč osmošolcev v Sloveniji povezana.

\section{Sklep}

V članku nas je zanimala povezava med stališči do vloge vere pri vplivu na družbo in povezava med pogostostjo obiskovanja verskih obredov zunaj doma z drugimi ljudmi v smislu religije oziroma vere kot katalizatorja politične oziroma družbene participacije (sem štejemo tako prostovoljstvo kakor elektorsko participacijo - pripravljenost voliti na volitvah, in pričakovano politično participacijo v prihodnje). Prav tako nas je zanimalo, ali obstaja povezava med stališči osmošolcev do vloge vere v družbi in evropsko identiteto. Populacija, ki smo jo preiskovali, so osmošolci v Sloveniji. Vse podatke za našo analizo smo zbrali v okviru zadnjega zajema Mednarodne raziskave državljanske vzgoje in izobraževanja (ICCS 2016). Vprašanja, ki zadevajo vero, so v izbirnem delu. V Sloveniji smo jih prvič vključili v raziskavo prav v zadnjem ciklu izvedbe raziskave.

$\checkmark$ raziskavi ICCS 2016 se je približno 72 \% osmošolcev v Sloveniji opredelilo kot verujočih (okoli 58 \% vseh učencev, sodelujočih v raziskavi, je navedlo, da so katoliške veroizpovedi), približno $28 \%$ pa se jih je opredelilo kot neverujočih (Klemenčič, Mirazchiyski in Novak 2019, 45). Okoli 32 \% osmošolcev je povedalo, da se verskih obredov zunaj doma z drugimi ljudi udeleži vsaj enkrat na leto, na drugi strani se teh obredov nikoli ne udeleži okoli 24 \% osmošolcev v Sloveniji (46). 
Naše dodatne analize so pokazale, da imajo osmošolci v Sloveniji, ki pogosteje obiskujejo verske obrede zunaj doma, tudi pozitivnejše mnenje o vlogi vere pri vplivu na družbo. Prav tako so rezultati pokazali na resda šibko, vendar pozitivno in statistično značilno povezanost med obiskovanjem verskih obredov zunaj doma s pripravljenostjo na prostovoljstvo za pomoč ljudem v skupnosti v prihodnje (ne nazadnje tudi povezavo s prostovoljstvom do sedaj). Zaznana je bila tudi povezava med stališči osmošolcev o vlogi vere kot vplivu na družbo in občutkom evropske identitete osmošolcev.

Članek prinaša pomembne ugotovitve, ki so v skladu z raziskavami, resda na drugih populacijah, v svetu. Zato je ta del rezultatov pričakovan. Lahko pa smo jih prvič empirično preverili tudi za Slovenijo. Pomembne so iz te perspektive, da bi nemara v nekem vsakodnevnem razmisleku celo menili, kako med prakticiranjem verskih obredov osmošolcev in njihovo, predvsem politično, participacijo ni nobene povezave (zato so nas naši rezultati vsaj delno presenetili). Pri prostovoljstvu bi verjetno to povezavo laže predvideli. Pa so rezultati analiz pokazali na povezavo pri prav vseh izračunanih korelacijah, čeprav ponekod nekoliko šibkejšo, a še vedno govorimo o statistično značilni povezanosti. Seveda moramo omeniti tudi, da pri tovrstnih raziskavah - verjetno bi to lahko trdili za večino ali celo vsako družboslovno raziskavo - rezultatov ne moremo interpretirati v smislu kavzalnosti, na način, da bi iskali vzrok in posledico. Najbrž to ni niti tako pomembno, vsekakor je pa pomembno spoznanje, da je med religioznostjo (recimo udeleževanje verskih obredov) in sedanjo in prihodno pripravljenostjo, participirati v družbi, povezava, ki je statistično značilna. Kot argument bi lahko navedli tudi to, da je participacija pri bolj verskih dejavnostih pomemben del grajenja aktivne participacije $v$ prihodnje, participacije $v$ smislu sodelovanja $v$ družbenem življenju, ki ima seveda različne perspektive. Pri tem ne govorimo le o aktivni participaciji v političnem življenju, čeprav smo potrdili tudi to povezavo. $\checkmark$ tem oziru so rezultati vsekakor pomembni za slovenski šolski sistem. Dajejo namreč vpogled v to, da govorimo o dveh področjih našega življenja (vera, politična participacija), ki se na prvi pogled zdita ločeni, pa očitno nista. To je vsekakor pomembno za nadaljnji razvoj področja državljanske vzgoje v Sloveniji. V publikacija Razvoj državljanske vzgoje v Sloveniji (Čepič et al. 2012, 166) avtorji predlagajo, »da se vsebina etika in vednost o verstvih izločita iz učnega načrta za državljansko vzgojo « in »da dobita mesto kot samostojna obvezna predmeta, saj bodo samo v tem okviru vsebine etike in poznavanja verstev dobile tisti minimalni obseg, ki jima glede na vsebino splošne izobrazbe in primerjave z drugimi državami gre«. Naši rezultati temu na eni strani pritrjujejo, češ kako pomembne so te vsebine v kurikulumu (zato se vsekakor strinjamo, da morajo tudi vsebine o verstvih imeti svojo vlogo v kurikulumu), vendar po drugi strani, morda se zdi paradoksno, temu lahko celo nasprotujejo. Rezultati so namreč pokazali, da govorimo o dveh sklopih (politična participacija in vera), ki sta očitno povezana. 


\section{Reference}

Čepič, Mitja, Janez Justin, Eva Klemenčič, Zdenko Kodelja, Mitja Sardoč, Marjan Šimenc in Darko Štrajn. 2012. Razvoj državljanske vzgoje v Republiki Sloveniji: konceptualni okvir in razvoj kurikulumov (državljanska vzgoja in etika, družba). Ljubljana: Pedagoški inštitut.

Dinham, Adam, in Martha Shaw. 2017. Religious Literacy through Religious Education: The Future of Teaching and Learning about Religion and Belief. Religions 8, št. 7:119.

Globokar, Roman, in Tadej Rifel. 2017. Medverski dialog pri religijskem pouku v Sloveniji. Bogoslovni vestnik 77, št. 2:357-368.

Golob, Tea, Matej Makarovič in Matevž Tomšič. 2019. Pomen religioznosti za evropsko identiteto mladih. Bogoslovni vestnik 80, št. 1:161175.

Klemenčič, Eva, Plamen V. Mirazchiyski in Jure Novak. 2019. Državljanska vzgoja v Sloveniji: Nacionalno poročilo Mednarodne raziskave državljanske vzgoje in izobraževanja (IEA ICCS 2016). Ljubljana: Pedagoški inštitut.

Mirazchiyski, Plamen, in INERI. 2020. RALSA: R Analyzer for Large-Scale Assessments. R package version 0.90.1. Vodnik po računalniškem programu. https://CRAN.R-project.org/ package=RALSA (pridobljeno 14. 6. 2020).

Pancer, S. Mark. 2015. The Psychology of Citizenship and Civic Engagement. Oxford: Oxford University Press.

Pevec Rozman, Mateja. 2017. Pomen in vloga religije v sodobni postmoderni družbi in iskanje bistva religioznega fenomena. Bogoslovni vestnik 77, št. 2:289-301.
Schulz, Wolfram, John Ainley, Julian Fraillon, Bruno Losito in Gabriella Agrusti. 2016. IEA International Civic and Citizenship Education Study 2016: Assessment Framework. Masterdam: The International Association for the Evaluation of Educational Achievement.

Schulz, Wolfram, John Ainley, Julian Fraillon, Bruno Losito, Gabriella Agrusti in Tim Friedman. 2018. Becoming Citizens in a Changing World: IEA International Civic and Citizenship Education Study 2016 International Report. New York: Springer Open.

Smith, Christian, in Robert Faris. 2002. Religion and American Adolescent Delinquency: Risk Behaviors and Constructive Social Activities; National Study of Youth and Religion, CB \#3057. Chapel Hill, NC: The University of North Carolina.

Udovič, Boštjan. 2020. ,Mass for the Homeland': (Just) a Religious Ceremony or a Religious, Diplomatic and Statehood Strengthening Activity? Bogoslovni vestnik 80, št. 1:145-159.

Zaff, F. Jonathan, Kristin A. Moore, Angela Romano Papillo in Stephanie Williams. 2003. Implications of Extracurricular Activity Participation During Adolescence on Positive Outcomes. Journal of Adolescent Research 18, št. 6:599630. 